\title{
ALGUNS COMENTÁRIOS A RESPEITO DAS REFORMAS RECENTES NO FIES E OS DESAFIOS ATUAIS
}

Manoel Pires ${ }^{1}$

\section{INTRODUÇÃO}

O Fundo de Financiamento ao Estudante do Ensino Superior (Fies) é o principal programa de financiamento de ensino superior do Brasil. Para parte significativa da população, o crédito estudantil é a segunda decisão de consumo mais importante, perdendo apenas para a aquisição de um imóvel.

Do ponto de vista teórico, a racionalidade para intervenção estatal nesse mercado é muito clara. A expansão da escolaridade média da população é um fator importante do desenvolvimento econômico, incentiva a maior produtividade da mão de obra, a inovação, a redução da criminalidade etc. As externalidades positivas são incontroversas. Além disso, esse é um mercado em que o crédito é extremamente escasso, pois a maior parte dos estudantes não possui condições de oferecer garantias adequadas e a renda futura é muito incerta. Por essas razóes, o sistema de crédito público subsidiado é a norma nesse segmento.

Do ponto de vista prático, a implementação desses programas é um enorme desafio. Os subsídios são elevados e a taxa de inadimplência bastante significativa. Em vários casos, há perdão para dívidas após certo prazo de pagamento. Mesmo nas melhores experiências e nos modelos mais modernos o custo fiscal é substancial.

O governo Obama, por exemplo, implementou uma grande reforma no sistema de crédito estudantil adotando o modelo income based repayment (IBR), no qual o estudante paga o financiamento a partir de uma fração do seu salário depois de formado e empregado. Mesmo com taxas de juros muito baixas, as dívidas se acumularam e as taxas de inadimplência também cresceram em função dos baixos salários praticados no mercado de trabalho americano no pós-crise.

No Brasil, houve notável expansão do programa entre 2011 e 2014, quando o número de novos contratos por ano saltou de 150 mil para mais de 700 mil. Naquele momento existiam quase 2 milhôes de contratos ativos. O crescimento se deu em função de condiçóes financeiras que se tornaram bastante favoráveis a partir de 2010 e da maior disponibilidade de vagas oferecidas ano após ano. Pelo lado da demanda por educação, o aumento do emprego criou expectativas nos estudantes de que a elevação da escolaridade elevaria a empregabilidade e os salários. Mas em função desse crescimento e do elevado custo fiscal, foi necessário rever o tamanho e o modelo do programa. ${ }^{2}$ Por conta disso, o governo federal, em 2015, revisou algumas normas.

\footnotetext{
1. Pesquisador na Faculdade de Economia, Administração, Contabilidade e Gestão de Políticas Públicas (FACE) da Universidade de Brasília (UnB) e coordenador do Observatório de Política Fiscal do Instituto Brasileiro de Economia da Fundação Getulio Vargas (IBRE/FGV). E-mail: <manoel.pires@fgv.br>.

2. Além de condições financeiras mais favoráveis, o que aumentava o subsídio por aluno, uma série de alterações permitiram que o fundo garantidor aumentasse sua alavancagem, o que viabilizou a expansão do número de vagas com maior concentração do risco de crédito na União. Ao longo dessas mudanças, o custo fiscal do programa aumentou consideravelmente. Em 2011, a estimativa é que tenha custado R\$1,9 bilhão, enquanto que, em 2017, já custava R\$ 30 bilhões. Atualmente, o passivo fiscal do programa - referentes a dívidas em atraso - gira em torno de R\$20 bilhões. Ver BRASIL. Ministério da Fazenda. Diagnóstico Fies. Brasília: MF, 2017. Disponível em: <https://goo.gl/Hntqh9>. Acesso em: 26 nov. 2018.
} 
A revisão do Fies foi estudada por um grupo de trabalhado criado para propor ajustes em várias políticas públicas, o Grupo de Trabalho para Acompanhamento do Gasto (GTAG) que desenvolveu mudanças para o Fies, o seguro defeso, o Benefício de Prestação Continuada (BPC), o auxílio doença, dentre outros programas.

No trabalho desenvolvido para o Fies é importante destacar o contexto político do país naquele momento, bem como o contexto do próprio programa. Em 2015, o país passava por uma crise política e o Congresso havia lançado a pauta bomba que representava um conjunto de assuntos de elevado impacto fiscal e desgaste do governo perante a sociedade. O Congresso Nacional ameaçava derrubar vários vetos presidenciais que até então nunca haviam sido apreciados. Em função desses acontecimentos era recomendável que se evitasse soluçóes técnicas que passassem por mudanças legais.

O programa, por sua vez, passava por uma crise. No final de 2014, o Ministério da Educação alterou a forma de repasse para as instituiçóes de ensino superior (IES), o que resultou em atraso dos desembolsos. Como as IES náo estavam mais recebendo os pagamentos conforme planejado, elas começaram a repassar alguns custos para os alunos, cancelaram algumas matrículas e, ao mesmo tempo, acionaram o Ministério da Educação (MEC) na justiça.

A insatisfação social foi grande e diante das dificuldades financeiras do governo, houve receios de que o programa sofresse um grande abalo. Dessa forma, a prioridade do GTAG era construir uma soluçáo técnica que não utilizasse um caminho legislativo e que viabilizasse financeiramente o programa para ser utilizado já no segundo semestre de 2015 .

\section{AS PRINCIPAIS MUDANÇAS NA REFORMA DE 2015}

Os estudos iniciais recomendavam a adoção dos modelos em que o pagamento do financiamento é contingente à renda do devedor. Esse modelo, com várias nuances, é utilizado nos Estados Unidos, Reino Unido e Austrália e o estudante amortiza a dívida a partir de um percentual do seu salário depois de formado e empregado. Algumas questôes críticas impediram que se seguisse aquele caminho na época. A primeira era que a experiência brasileira com financiamentos cuja amortizaçáo ocorria de forma contingente à renda náo era auspiciosa. Nos anos 1960, por exemplo, os contratos de financiamento imobiliário possuíam essa característica o que levou os mutuários a subdeclararem suas rendas. Com isso, os financiamentos não eram quitados. A solução foi criar o Fundo de Compensação de Variaçôes Salariais (FCVS) em que a União assumiu o compromisso de honrar esses contratos. A conta é paga pelo Tesouro até hoje.

Essa crítica poderia ser relativizada se fosse possível integrar as informaçóes de renda com a Receita Federal. Infelizmente, não foi possível, construir essa solução a tempo. A experiência sugere que é necessário bastante tempo para que os sistemas de informação do setor público sejam aperfeiçoados. O E-social, por exemplo, levou muitos anos para se tornar operacional. De todo o modo, é importante avançar na integração dos sistemas de tributação para aperfeiçoar o desenho das políticas públicas.

A reforma foi feita, portanto, combinando o que era possível absorver da experiência internacional do funcionamento prático do programa e a realidade brasileira do momento.

Dentre as mudanças mais importantes estão o realinhamento dos critérios de renda, o fim do financiamento integral, o aumento das coparticipaçóes e da taxa de juros e a reduçáo do número de vagas. Buscava-se dessa maneira contemplar três objetivos: reduzir os custos do programa, realinhar os incentivos e melhorar a governança. Estimava-se que o subsídio por aluno cairia em 30\% no modelo novo.

Antes da reforma, $80 \%$ dos contratos eram de financiamento integral. Entre os problemas que isso criava estava o fato de que a dívida se tornava muito grande para ser paga e que muitos estudantes entendiam que 
haviam ganho uma bolsa e que não tinham que pagar um financiamento estudantil. Essa modalidade de financiamento foi encerrada.

O realinhamento das condiçóes financeiras levou a uma redefinição da taxa de juros pela remuneração da poupança e a definição de limites de comprometimento de renda com base na renda familiar bruta per capita. Os limites de comprometimento de renda foram definidos de forma progressiva para que as famílias mais ricas pudessem pagar seus financiamentos de forma mais célere enquanto para as famílias mais pobres o financiamento seria mais prolongado e o subsídio resultante seria maior. Essa foi, naquele momento, a forma possível de definir o pagamento como função da renda.

TABELA 1

Modelo de coparticipação

\begin{tabular}{lcccc}
\hline $\begin{array}{l}\text { Renda familiar bruta per capita } \\
\text { (RFB-PC) }\end{array}$ & $\begin{array}{c}\text { Comprometimento da RFB-PC } \\
\text { (com encagos educacionais - \%) }\end{array}$ & $\begin{array}{c}\text { Cofinanciamento } \\
\text { (parte a ser paga pelo aluno da } \\
\text { faixa superior - R\$) }\end{array}$ & $\begin{array}{c}\text { Financiamento curso médio } \\
(\%)^{1}\end{array}$ & Financiamento medicina (\%) \\
\hline Até 0,5 SM & 15 & 59,10 & 93,8 & 98,5 \\
$>0,5$ SM a 1 SM & 21 & 165,48 & 82,7 & 95,8 \\
$>1$ SM a 1,5 SM & 27 & 319,14 & 66,6 & 91,9 \\
$>1,5$ SM a 2,0 SM & 32 & 504,32 & 47,2 & 87,2 \\
$>$ 2,0 SM a 2,5 SM & 38 & 748,60 & 21,6 & 81,0 \\
\hline
\end{tabular}

Fonte: Pires (2015). ${ }^{3}$

Nota: ${ }^{1}$ Considera valores de 2014; custo médio de mensalidade em R\$955,00.

Um resultado dessa redefinição foi que os subsídios por faixa de renda se tornaram mais uniformes. Para verificar isso, o gráfico 1 apresenta o subsídio teórico de um contrato por faixa de renda. Ele é calculado como a diferença do fluxo de caixa nas condiçôes financeiras do programa em relaçáo a um fluxo de caixa cujo contrato é remunerado pela taxa Selic.

\section{GRÁFICO 1}

Subsídio do Fies por faixa de comprometimento de renda

$1 \mathrm{~A}$ - Modelo vigente até 2014

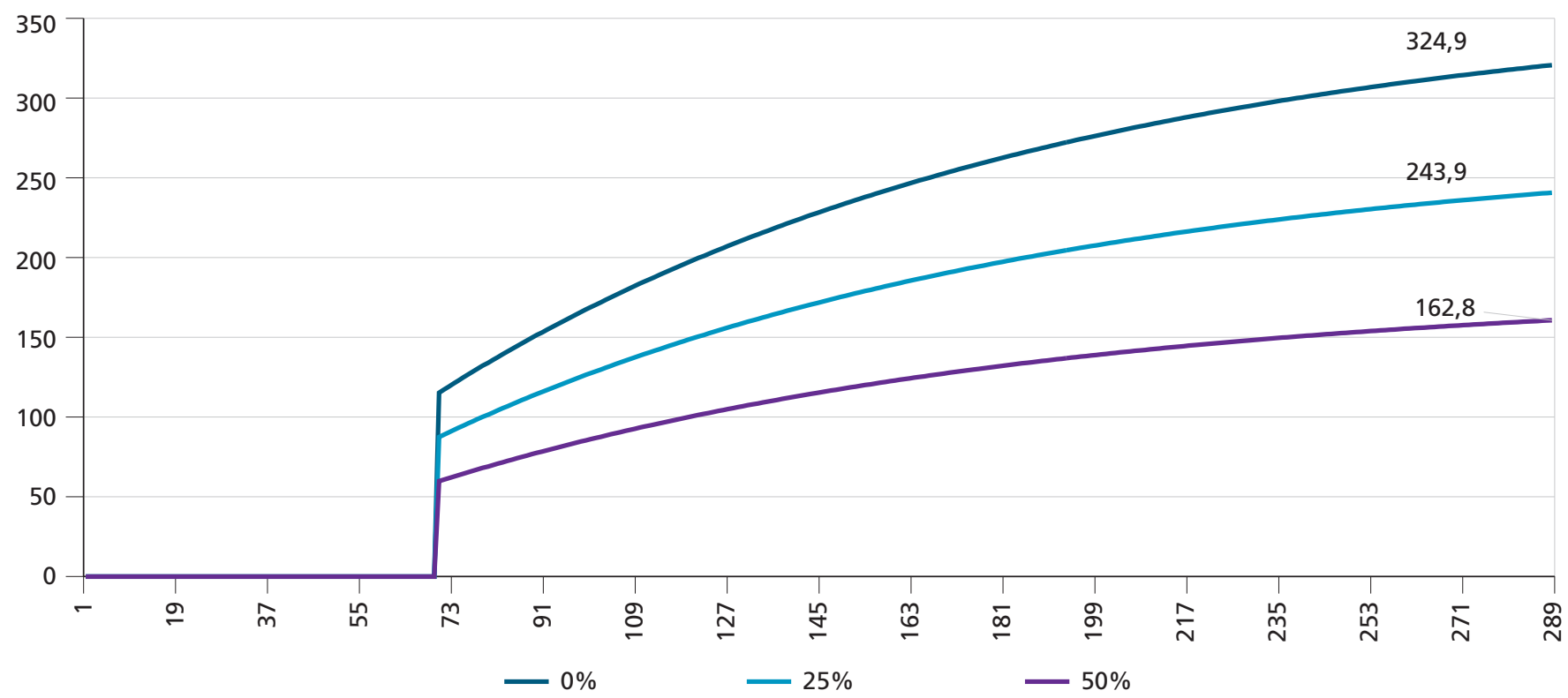


1B - Modelo vigente entre 2015 e 2017

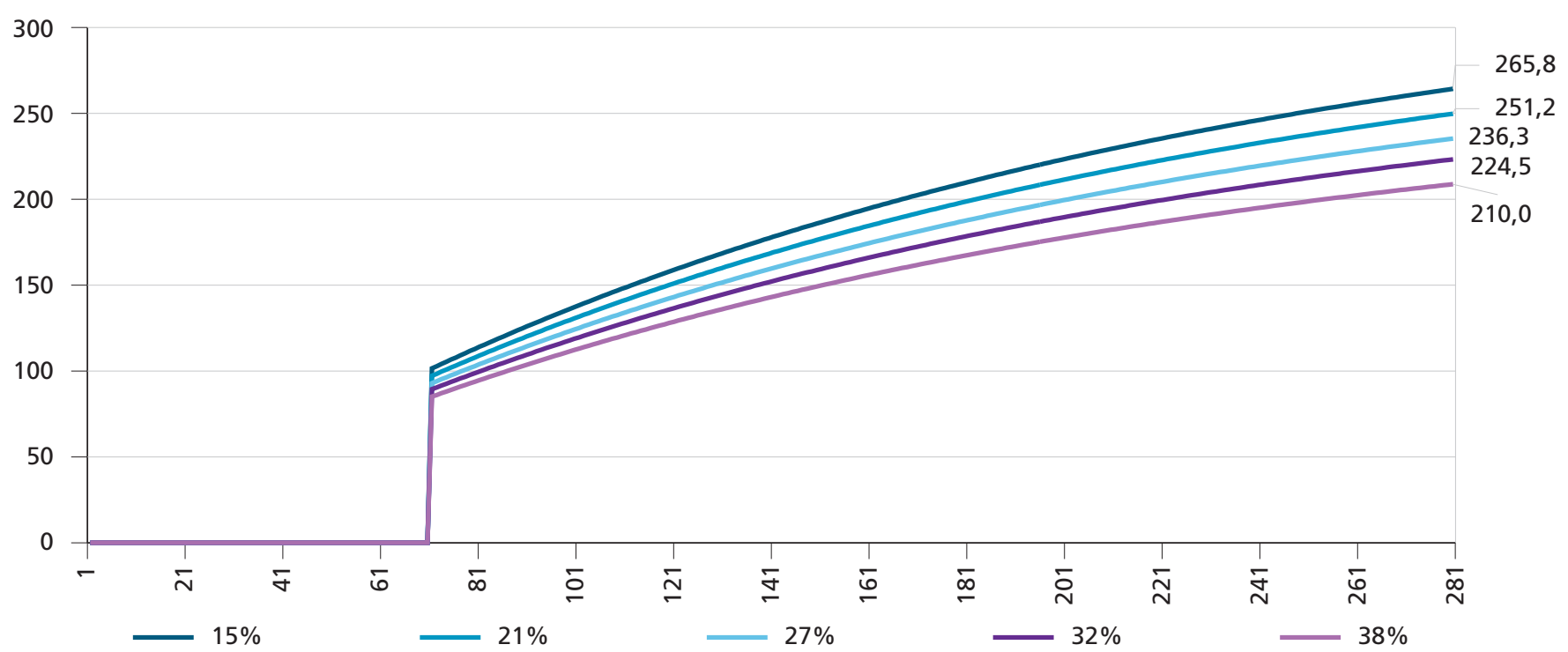

Fonte: Pires (2015).

No modelo vigente até 2014, é possível verificar que as três faixas de renda utilizadas para definir o contrato implicavam subsídios muito díspares entre cada uma. Como o subsídio presente no financiamento integral era muito superior aos demais, o incentivo era para que os estudantes subdeclarassem sua renda para entrar na modalidade mais favorecida.

Ao aumentar o número de faixas e reduzir os subsídios, esse incentivo foi bastante diminuído. Ainda assim, o programa continuou progressivo pois o subsídio da parcela final do contrato é $26 \%$ maior para os mais pobres em relação à maior parcela de comprometimento.

Além de revisar as condições financeiras do programa, uma outra forma de reduzir o custo é diminuir o número de contratos novos. Isso também foi feito em 2015 quando foram ofertadas 323 mil novas vagas, das quais 287 mil foram preenchidas. Isso representou menos de metade das vagas ofertadas no ano anterior. Na prática, o programa estava voltando ao tamanho que ele tinha em 2012. Para a frente, projetava-se um crescimento estável das vagas. A ideia era que se estabelecesse um planejamento de longo prazo para a abertura de novas vagas que reduzisse a incerteza do programa pelo lado da oferta.

\section{GRÁFICO 2}

Novas matrículas do Fies (2011-2024)

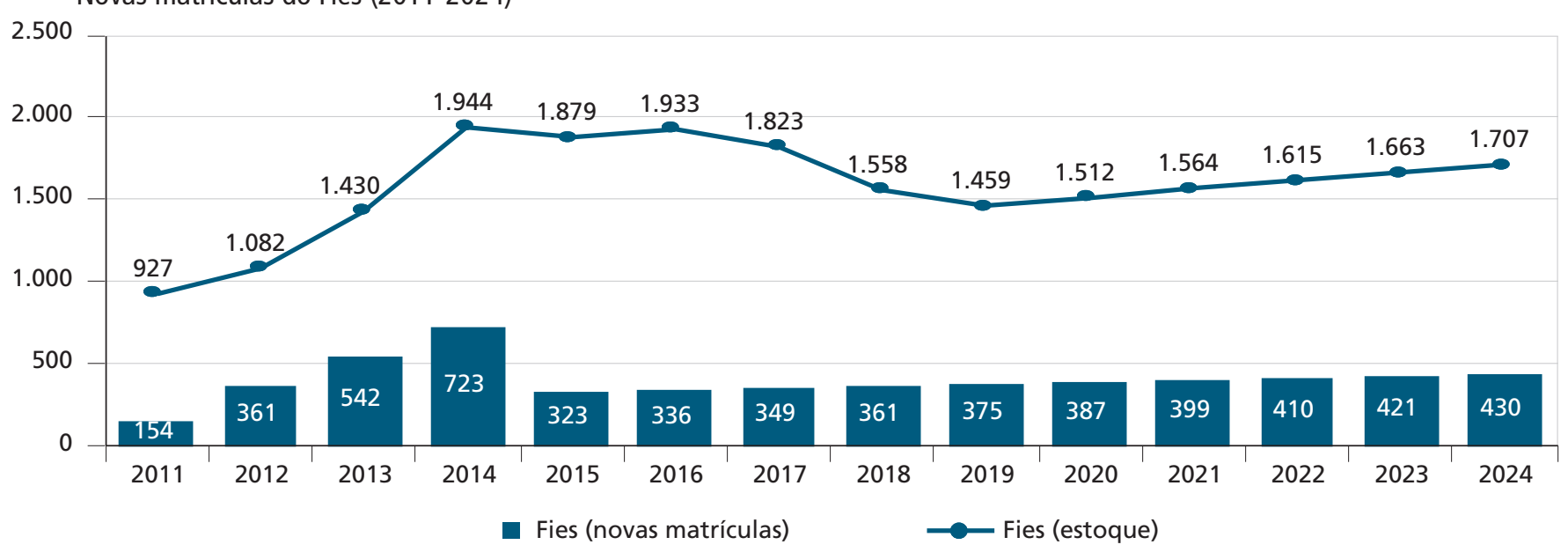




\section{A REFORMA DE 2017}

Em 2017, o governo federal propôs uma série de mudanças no Fies por intermédio da Medida Provisória n⿳o 785 . Dentre as principais mudanças está a possibilidade de que a amortização possa ser consignada em folha de pagamento, aproximando o programa ainda mais dos modelos contingentes à renda. As instituiçóes de ensino superior deverão elevar suas contribuições no Fundo Garantidor reduzindo a concentração de risco de crédito para a União. Isso na prática tende a elevar o custo da mensalidade para o aluno.

Uma outra mudança está na indexação da taxa de juros à inflação. Isso é comum em outros países e evita que a taxa real se torne negativa. ${ }^{4}$ Também foi criada uma modalidade do Fies a ser operada por bancos públicos e privados. Essa nova modalidade não deve ser responsável pela elevação substancial das matrículas já que por conta das características desse programa a iniciativa privada não costuma ter atuação relevante. De fato, o levantamento mais recente indicou que apenas 265 contratos foram fechados das 105 mil vagas disponibilizadas.

O Tesouro Nacional passou a explicitar as despesas com o Fies nas estatísticas fiscais. Esse foi um passo importante para aumentar a transparência do custo do programa. Por fim, foi criado um comitê interministerial para fortalecer a governança do programa. Essa é uma área importante para avanços, pois uma das razóes para o crescimento do custo fiscal do programa foi a falta de transparência do programa e a imperfeição dos indicadores de monitoramento. Mas a experiência prática com esses comitês no governo federal cria dúvidas sobre o sucesso dessa iniciativa.

\section{ALGUNS DESAFIOS}

A Medida Provisória no 785 , convertida na Lei n⿳o 13.530/2017, avançou na agenda introduzida pela reforma de 2015, revisando algumas condiçóes financeiras e a sustentabilidade de longo prazo do programa. Nesse sentido, em vários aspectos ela deu continuidade a esse conjunto de iniciativas.

$\mathrm{O}$ aspecto mais emergencial está em resolver o problema da inadimplência do Fies que gira em torno de $50 \%$, com risco fiscal aproximado de $\mathrm{R} \$ 20$ bilhóes. Atualmente, não há mecanismo de renegociação de dívida estudantil. Um estudante que possui parcelas atrasadas deve pagar toda a dívida à vista para regularizar sua situação. Um sistema como esse é um convite a inadimplência. Esses mecanismos são bastante comuns em outros países e deveria ser instituído no sistema brasileiro. A nova legislação possibilitou a renegociação que recentemente foi regulamentada pelo MEC. É importante acompanhar se esse processo vai ser bem sucedido. .

Uma outra iniciativa importante seria criar incentivos financeiros para pré-pagamento e estabelecer mecanismos progressivos de pagamento uma vez que os salários são mais baixos nas fases iniciais da carreira. Isso reduziria o risco de inadimplência e permitiria que os pagamentos fossem acelerados em momentos em que o mercado de trabalho estivesse mais favorável. Dessa forma, o governo recuperaria seus recursos de forma mais célere e em maior montante.

Apesar da explicitação das despesas nas estatísticas ser um passo importante para a transparência do programa, o efeito sobre a melhora da governança é muito pequeno. Isso ocorre porque há grande defasagem temporal entre a definição da política e o seu custo efetivo que só se materializa muito tempo depois. Nesse sentido, é importante que o orçamento traga informaçôes sobre o custo do programa no momento em que a política está sendo discutida entre o governo e o Congresso Nacional. Para isso, é necessário que a peça orçamentária apresente

4. Na prática, a mudança da taxa de caderneta de poupança para a taxa de inflação aumentou o subsídio. Como as taxas de juros são elevadas no Brasil, essa mudança pode implicar elevado subsídio. De todo o modo, evita situações que já ocorreram no passado em que a taxa real se tornou negativa. Se 0 financiamento estudantil efetivamente vier a caminhar para um financiamento contingente à renda, o juro real pode ser positivo, pois já haverá um subsídio garantido aos mais pobres, se o programa for desenhado com um perdão da dívida remanescente quando da aposentadoria ou morte do devedor. 
um capítulo sobre crédito público que traga informaçóes sobre os subsídios esperados, custo futuro total desses programas e demais custos financeiros no momento da definição das políticas.

As novas matrículas com financiamento do Fies estão em forte queda. No primeiro semestre deste ano apenas 54\% das 82 mil vagas foram preenchidas. Assim, em 2018 o número de novas matrículas deverá ser inferior a 100 mil de modo que o programa tem retrocedido na sua contribuição para a expansão da educação superior no Brasil. Isso é fruto da elevada taxa de desemprego que retira a confiança dos jovens no futuro fazendo com que adiem decisóes importantes como essa ou que considerem que a educação não é atraente, dado que imaginam que continuarão desempregados. Isso só vai se resolver com a melhora da economia. Mas do ponto de vista de desenho de política, é importante que se evite a rotina de mudanças muito drásticas no programa para que a desconfiança no Fies não aumente ainda mais. Nesse sentido, o ideal é que a adoção de modelos contingentes à renda ocorra de forma integral e não mais por parcelas. 